\title{
Mathematics: The Basis for Quantitative Knowledge
}

\author{
J. T. Trevors • M. H. Saier Jr.
}

Received: 1 December 2009 / Accepted: 2 December 2009 /Published online: 23 December 2009

(C) The Author(s) 2009. This article is published with open access at Springerlink.com

In this editorial, we consider the inference that mathematics has underpinned virtually all of science and engineering in the past and will become increasingly important in future research. Mathematics can be considered the foundation upon which humans can build an immense knowledge set to be used wisely for the good of humanity. In the pioneering days of science and technology, precise physical constants were discovered; explosive gun powder was prepared from the correct proportions of ingredients; temperature scales were designed; lenses for eye glasses, telescopes, and microscopes were precisely constructed; and the shapes and sizes of living organisms, cells, tissues, and organs were determined. Math was used to understand the rates of biochemical reactions, inhibitor effects, and the therapeutic doses of prescription drugs. We know the sizes of the elements in the periodic table and the charges and sizes of elemental particles making up matter. We know the estimated masses of planetary bodies and some galaxies, the speed of light, how to smash particles, and the ages of fossils. We use math

J. T. Trevors $(\bowtie)$

School of Environmental Sciences, University of Guelph, Guelph, ON N1G 2W1, Canada

e-mail: jtrevors@uoguelph.ca

M. H. Saier Jr. $(\bowtie)$

Division of Biological Sciences, University of California, San Diego,

La Jolla, CA 92093-0116, USA

e-mail: msaier@ucsd.edu and more maths in every aspect of our daily lives. Check, for example, the use of math on a cereal box.

The evidence leading up to recognition of DNA as the genetic material of all cells required X-ray diffraction data, a knowledge of the numbers of hydrogen bonds between base pairs, and the mathdependent construction of models to solve DNA structural conformations. These advances, in turn provided an explanation for the precise mechanisms for replication of genetic material and transcription and translation of genes into mRNA and proteins.

Math is everywhere. It comprises a language of its own that we have integrated into all our other languages. It allows us to make rational decisions and function on a day-to-day basis. We keep records and accounts to manage our routine and extraordinary activities. We can know what time it is in any time zone on Earth because of math. We can even estimate how much money one can save over a 10-year period by eating as a vegetarian rather than an omnivore, or what each of our contributions to global warming is, depending on our lifestyles.

We use math to make predictions about the future. In fact, we have tremendous predictive powers. In recent years, math and mathematical modeling have become important approaches to understanding some of humanity's most pressing problems. In fact, the use of math in predicting human population growth and understanding the crisis of global climate change are literally in the news daily. We can even estimate when the Earth will become too hot for human existence. 
The use of math via computer systems is now used for making short- and long-term weather predictions, tracking hurricanes and tornadoes, estimating world food reserves and agricultural productivity, the speed of pandemic spread, the percentages of infected individuals, and the numbers of resultant deaths.

Mathematics is central to understanding interconnected problems facing all of humanity. These problems, for example, concern the effects of human population growth on resource depletion and subsequent pollution of our biosphere. Without math, relevant calculations would be impossible. We have projections of human population growth, resource depletion, the numbers of humans without the basic necessities of life, and death rates from flooding and extreme weather conditions. We have reasonably reliable methods to calculate rates of polar ice melting, increases in average global temperatures, rates of consumption of our limited energy sources, and consequent rates of build-up of atmospheric greenhouse gases, and the consequences of rising sea levels. We can estimate (with accuracy decreasing with increasing time into the future) the times when coastal cities will be flooded and human populations must migrate. So far, unfortunately, most early estimates have proven to be too conservative, and each revision brings with it recognition that we have less time to act than had previously been claimed.

Some of these statistics are not pleasant to think about, and even more difficult to deal with. However, without the use of math, humans would have no way to recognize the correct solutions. There is one interconnected problem that is causative of all the others: human population growth. The math is straightforward. Too many humans producing too much pollution equates to continued disaster. Every human on the planet can understand this essential precept, but too many politicians and corporate executives strive only to make money, even at the expense of humankind. Short-sightedness allows them to do so. We already have too many people and too much total global pollution. The prospect of sustainability may already be past the tipping point.

Open Access This article is distributed under the terms of the Creative Commons Attribution Noncommercial License which permits any noncommercial use, distribution, and reproduction in any medium, provided the original author(s) and source are credited. 